Tropical Journal of Pharmaceutical Research November 2021; 20 (11): 2395-2400

ISSN: $1596-5996$ (print); 1596-9827 (electronic) (C) Pharmacotherapy Group, Faculty of Pharmacy, University of Benin, Benin City, 300001 Nigeria

\title{
Effect of budesonide aerosol inhalation on postoperative complications and foreign body sensation in the throat of goiter resection patients
}

\author{
Yijun Chen ${ }^{1 *}$, Guolie Zhang1, Yuanmei Lin ${ }^{1}$, Guoliang Zhang1, Lifen Lin², \\ Huiying $\mathrm{YaO}^{3}$, Jinfan Zhang ${ }^{4}$ \\ ${ }^{1}$ First Department of Thyroid Surgery, ${ }^{2}$ Operation Room, ${ }^{3}$ Neurology Department, ${ }^{4}$ Department of Breast Surgery, The Affiliated \\ Hospital of Putian University, Putian 351100, Fujian, China \\ *For correspondence: Email: chenyijun1987@126.com, winoudzhang@gmail.com Tel: +086 0594-2293910
}

Sent for review: 19 June 2021

Revised accepted: 6 October 2021

\begin{abstract}
Purpose: To study the effect of budesonide aerosol inhalation on postoperative complications and foreign-body sensation in the throat of patients who underwent goiter resection.

Methods: One hundred and twenty patients who underwent goiter resection at The Affiliated Hospital of Putian University (Fujian, China) from January 2019 to January 2020 were included in the study, and then equally and randomly assigned to groups $A$ and $B$. During the perioperative period, group $A$ patients were given budesonide aerosol inhalation, while group $B$ patients received aerosol inhalation of equivalent volume of normal salineectively. Postoperative complication rate (CR), complication pain scores, scores on mucosal response in the throat, and scores on foreign body sensation in the throat were determined for both groups.

Results: Postoperative complications in patients were hoarseness, sore throat and cough. Group A had significantly lower postoperative $C R$, lower complication pain scores, lower scores on mucosal response in the throat, and lower scores on foreign body sensation in the throat, when compared to group $B(p<$ 0.001).

Conclusion: Budesonide aerosol inhalation in patients who underwent goiter resection is effective in relieving throat injury from general anesthesia, minimizing likelihood of postoperative complications, and easing foreign-body sensation in the throat. Thus, this strategy may be suitable for the management of postoperative complications.
\end{abstract}

Keywords: Budesonide, Aerosol inhalation, Thyroid postoperative complications

\begin{abstract}
This is an Open Access article that uses a funding model which does not charge readers or their institutions for access and distributed under the terms of the Creative Commons Attribution License (http://creativecommons.org/licenses/by/4.0) and the Budapest Open Access Initiative (http://www.budapestopenaccessinitiative.org/read), which permit unrestricted use, distribution, and reproduction in any medium, provided the original work is properly credited.
\end{abstract}

Tropical Journal of Pharmaceutical Research is indexed by Science Citation Index (SciSearch), Scopus, International Pharmaceutical Abstract, Chemical Abstracts, Embase, Index Copernicus, EBSCO, African Index Medicus, JournalSeek, Journal Citation Reports/Science Edition, Directory of Open Access Journals (DOAJ), African Journal Online, Bioline International, Open-J-Gate and Pharmacy Abstracts

\section{INTRODUCTION}

Goiter is found mostly among female patients, and it is generally treated with surgical resection in the clinic. However, patients experience throat discomfort and foreign body sensation caused by the intraoperative intubation of general anesthesia, and even suffer from more serious postoperative complications, leading to a greatly reduced operative effect [1-3]. Aerosol inhalation of glucocorticoids is an important means of relieving throat inflammation. Glucocorticoids are 
preliminarily applied in the postoperative treatment of patients with throat diseases [4-6]. However, few theoretical studies linking glucocorticoids with postoperative complications in patients who underwent goiter resection have been published. In addition, not much is known about the potential of a glucocorticoid such as budesonide to reduce the incidence of postoperative complications in patients.

The present study was carried out to investigate the effect of budesonide aerosol inhalation on postoperative complications and foreign-body sensation in the throat of patients who underwent goiter resection.

\section{METHODS}

\section{General information on patients}

A total of 120 patients who underwent goiter resection at The Affiliated Hospital of Putian University (Fujian, China) from January 2019 to January 2020 were chosen for the study. They were equally and randomly divided into two groups: groups $\mathrm{A}$ and $\mathrm{B}$. The study was conducted in accordance with the Declaration of Helsinki (as revised in 2013) [7]. The study received the approval of the Ethics Committee of The Affiliated Hospital of Putian University (approval no. $=20181146$ ). Patients and/or their family members were fully briefed on the study process and signed the informed consent forms.

\section{Inclusion criteria}

Patients who met the following criteria were included: those who were diagnosed with goiter through medical examination, and were treated surgically; those with normal articulation and no other throat diseases, and those who underwent orotracheal intubation under general anesthesia.

\section{Exclusion criteria}

Patients who met the following criteria were excluded: those with mental problems or communication disorders; patients with other organic diseases, those with abnormal levels of plasma calcium, and those for whom the duration of intubation for general anesthesia was under 1 h.

\section{Treatments}

During the perioperative period, group A was given budesonide aerosol inhalation, while group $B$ was given aerosol inhalation of equivalent volume of normal saline, with the following specific steps: At $1 \mathrm{~h}$ before operation, $7 \mathrm{~h}$ after operation, and $24 \mathrm{~h}$ after operation, group $\mathrm{A}$ received $2 \mathrm{mg}$ of budesonide suspension (CHIA TAI TIANQING Pharmaceutical Group Co. Ltd; NMPA approval no. H20203063) via aerosol inhalation driven by oxygen, at an oxygen flow rate of $6 \mathrm{~L} / \mathrm{min}$. At the same time points, group $B$ received equivalent amount of normal saline via aerosol inhalation. Comprehensive nursing and preventive measures were given to patients in both groups to avoid the factors that could affect the study results.

\section{Evaluation of treatment outcomes}

\section{Postoperative complication rate (CR)}

The complications included dyspnea, hoarseness, incision site infection, numbness of hands and feet, subcutaneous emphysema, sore throat and cough. The number of patients with complications was recorded.

\section{Pain complication score}

At 1, 7 and $24 \mathrm{~h}$ after operation, a visual analogue scale of pain complication was applied (0-100 points), with lower scores suggesting lower pain sensation caused by the symptoms [8-11].

\section{Score on mucosal reaction in the throat}

This was calculated based on the WHO grading of mucosal reaction at 1,7 and $24 \mathrm{~h}$ after operation $[12,13]$.

\section{Score of foreign body sensation in the throat}

This was rated on a scale of $0-10$ at 1,7 and 24 $\mathrm{h}$ after operation, with the self-prepared scale of The Affiliated Hospital of Putian University.

\section{Statistical analysis}

The data were processed using SPSS20.0 software. GraphPad Prism 7 (GraphPad Software, San Diego, USA) was used for graphics. Enumeration data and measurement data were included. Statistical analysis was done using $X^{2}$ test and $t$-test. Differences were considered statistically significant at $p<0.05$.

\section{RESULTS}

\section{Patients' general profile}

No marked differences in the general information were observed between the two groups $(p>$ 0.05). These results are shown in Table 1. 


\section{Patients' postoperative CR}

As shown in Table 2, there were no cases of dyspnea, incision site infection, numbness of hands and feet or subcutaneous emphysema in patients in both groups. Compared with group $B$, fewer patients in group $A$ suffered from hoarseness, sore throat and cough, which were the main symptoms $(p<0.001)$.

\section{Pain complication scores}

Hoarseness pain scores were $8.59 \pm 1.21,6.51 \pm$ 2.21 and $1.88 \pm 0.56$ in group $A$ at $1 \mathrm{~h}, 7 \mathrm{~h}$ and $24 \mathrm{~h}$ after operation, while the corresponding scores for group B were $30.56 \pm 5.89,29.11 \pm$ 4.57 and $17.55 \pm 4.58$. Throat pain scores in group A were $25.65 \pm 3.21,21.12 \pm 3.55$ and $17.62 \pm 2.54$ at $1 \mathrm{~h}, 7 \mathrm{~h}$ and $24 \mathrm{~h}$ after operation, while the corresponding scores in group $B$ were $60.55 \pm 12.56,58.56 \pm 15.45$ and $42.15 \pm 6.25$. Cough pain scores were $1.42 \pm 0.56,3.12 \pm 1.12$ and $2.21 \pm 0.54$ in group $A$ at $1 \mathrm{~h}, 7 \mathrm{~h}$ and $24 \mathrm{~h}$ operation after, while the corresponding scores for group B were $2.31 \pm 0.54,4.01 \pm 0.27$ and $2.89 \pm 0.68$. The pain complication scores were markedly lower in group A compared with group B $(p<0.001)$, as presented in Figures $1-3$.

\section{Comparison of patients' scores on mucosal response in the throat}

The scores on mucosal response in the throat were markedly lower in group $A$ than in group $B$ $(p<0.001)$, as presented in Table 3.

Table 1: Comparison of patients' general information

\section{Scores on foreign body sensation in the throat}

As shown in Table 4, scores on foreign body sensation in the throat were lower in group $A$ than in group B $(p<0.001)$.

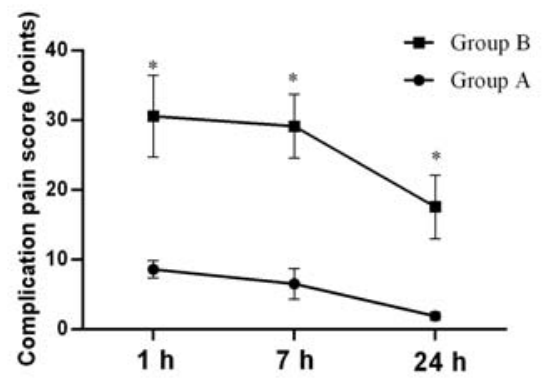

Figure 1: Comparison of patients' hoarseness pain scores (points). Data are presented as mean \pm SD. ${ }^{\star} P$ $<0.001$, hoarseness pain scores in group $A$ vs scores in group $B$

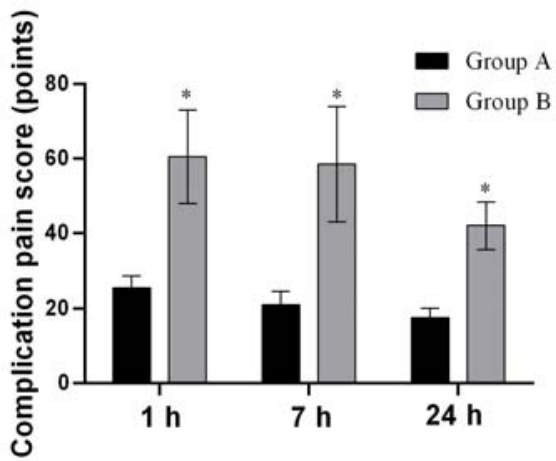

Figure 2: Comparison of patients' throat pain scores (points). Data are presented as mean \pm SD. ${ }^{*} p<$ 0.001 , throat pain scores in group $A$ vs scores in group B

\begin{tabular}{lcccc}
\hline Group & Group A $(\mathbf{n}=\mathbf{6 0})$ & Group B $\mathbf{n}=\mathbf{6 0})$ & $\mathbf{X}^{\mathbf{2}} / \mathbf{t}$ & $\boldsymbol{P}$-value \\
\hline Gender & 5 & 6.100 & 0.752 \\
Male & 55 & 54 & & \\
Female & & & & \\
Age (years) & $22-74$ & $23-74$ & & 0.986 \\
Range & $41.21 \pm 6.20$ & $41.23 \pm 6.21$ & 0.018 & 0.803 \\
Mean age & 10 & 9 & 0.063 & 0.752 \\
Hypertension & 6 & 5 & 0.100 & 0.855 \\
Coronary heart disease & & & & 0.831 \\
Swelling classification & 31 & 30 & 0.033 & 0.046 \\
Thyroid adenoma & 14 & 15 & 0.058 & 0.810 \\
Thyroid nodular goiter & 10 & 11 & 0.120 & 0.729 \\
Thyroid hyperfunction & 5 & 4 & 0.034 & 0.853 \\
Hashimoto's disease & & & & \\
Anesthesia grade & 35 & 34 & & \\
$I$ & 25 & 26 & & \\
II & & & & \\
\hline
\end{tabular}


Table 2: Comparison of patients' postoperative CR [n (\%)]

\begin{tabular}{lcccc}
\hline Group & Hoarseness & Sore throat & Cough & Total incidence \\
\hline $\mathrm{A}$ & $5(8.3)$ & $10(16.7)$ & $2(3.3)$ & $17(28.3)$ \\
$\mathrm{B}$ & $12(20.0)$ & $32(53.3)$ & $10(16.7)$ & $54(90.0)$ \\
$\mathrm{X}^{2}$ & 3.358 & 17.729 & 5.926 & 47.221 \\
$P$-value & 0.067 & 0.000 & 0.015 & 0.000 \\
\hline
\end{tabular}

Table 3: Comparison of patients' scores on mucosal response in the throat (points)

\begin{tabular}{lcccc}
\hline Time after operation $(\mathbf{h})$ & Group A & Group B & $\boldsymbol{t}$ & $\boldsymbol{P}$-value \\
\hline 1 & $2.56 \pm 1.21$ & $5.30 \pm 1.26$ & 12.149 & 0.000 \\
7 & $2.55 \pm 1.50$ & $5.31 \pm 1.24$ & 10.985 & 0.000 \\
24 & $0.68 \pm 0.01$ & $3.65 \pm 1.58$ & 14.560 & 0.000 \\
\hline
\end{tabular}

Data are presented as mean \pm SD

Table 4: Comparison of scores on foreign body sensation in throat

\begin{tabular}{lcccc}
\hline Time & Group A & Group B & $\boldsymbol{t}$ & $\boldsymbol{P}$-value \\
\hline 1 $\mathrm{h}$ after operation & $3.01 \pm 1.00$ & $5.35 \pm 1.32$ & 10.945 & 0.000 \\
7 h after operation & $2.85 \pm 1.45$ & $5.20 \pm 1.15$ & 9.836 & 0.000 \\
24 h after operation & $1.12 \pm 0.56$ & $3.42 \pm 1.67$ & 10.115 & 0.000 \\
\hline
\end{tabular}

Values are mean $\overline{ \pm} \mathrm{SD}$

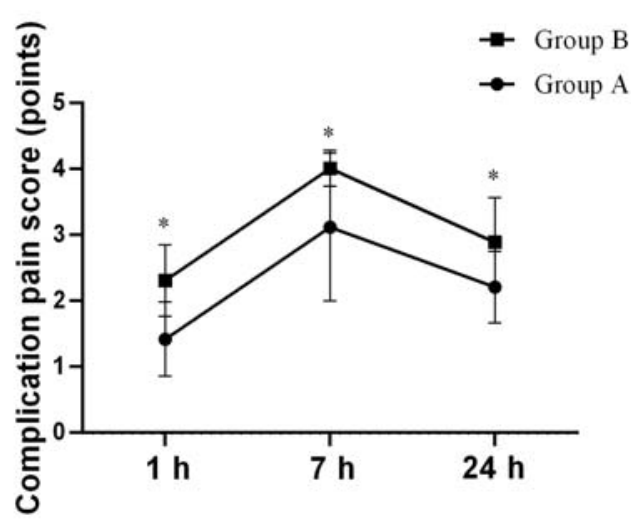

Figure 3: Comparison of patients' cough pain scores (points). Data are presented as mean \pm SD. ${ }^{*} p<$ 0.001 , cough pain scores in group $A$ vs scores in group B

\section{DISCUSSION}

Discomfort and foreign body sensation in the throat are typical complaints of patients after general anesthesia through oral intubation. Compared with other patients, those who underwent goiter resection often show more serious symptoms in the throat [14-15]. In this study, the postoperative complications included hoarseness, sore throat and cough, with more number of patients having sore throat than the number of patients with the other two complications. This may be due to the fact that foreign body sensation in the throat increases the frequency of swallowing. Therefore, the patients in group B swallowed more often and had higher throat pain scores.
Since sore throat is the most common postoperative reaction in goiter resection, many scholars in academia have carried out studies to investigate the influence of different drugs on the symptom. Some research results showed that preoperative administration of drugs worked well in prevention, and reduced the possibility of postoperative sore throat $[16,17]$. Therefore, preoperative administration was selected in this study, and the results showed that the probability of sore throat was lower than that obtained in general research.

Different drugs have different effects on patients' postoperative symptoms. Budesonide relieves the irritation to the throat during intubation under general anesthesia, lowers the release frequency of inflammatory mediators, and reduces vascular permeability, thereby lowering the degree of mucosal exudation in the throat and reducing the possibility of sore throat. Therefore, group A achieved markedly lower scores of mucosal response and foreign body sensation in the throat, relative to group B. In a study by Seitz, budesonide aerosol inhalation was given to patients who underwent goiter resection in the experimental group, while aerosol inhalation of normal saline was given to those in the control group. The results showed that the scores of mucosal response in the throat of the experimental group at 1,7 and $24 \mathrm{~h}$ after operation were $2.51 \pm 1.15,2.45 \pm 1.56$ and 0.72 \pm 0.05 , which were markedly lower than the corresponding scores in the control group [18]. This is in line with present study. Thus, budesonide played an active role in relieving patients' throat discomfort and foreign body sensation.

Trop J Pharm Res, November 2021; 20(11): 2398 


\section{Limitations of the study}

It should be noted that the hoarseness of patients in group A was milder. However, this study did not deeply investigate the relationship between budesonide and hoarseness. This needs to be further confirmed in subsequent studies.

\section{CONCLUSION}

Budesonide aerosol inhalation reduces the possibility of postoperative complications and eases throat discomfort and foreign body sensation in patients who underwent goiter resection. Thus, this treatment strategy may be suitable for the management of postoperative complications.

\section{DECLARATIONS}

\section{Conflict of Interest}

No conflict of interest associated with this work.

\section{Contribution of Authors}

The authors declare that this work was done by the authors named in this article and all liabilities pertaining to claims relating to the content of this article will be borne by them.

\section{Open Access}

This is an Open Access article that uses a funding model which does not charge readers or their institutions for access and distributed under the terms of the Creative Commons Attribution License (http://creativecommons.org/licenses/by/ 4.0) and the Budapest Open Access Initiative (http://www.budapestopenaccessinitiative.org/rea d), which permit unrestricted use, distribution, and reproduction in any medium, provided the original work is properly credited.

\section{REFERENCES}

1. Castro-Rodriguez JA, Pincheira MA, Escobar-Serna DP, Sossa-Briceño MP, Rodriguez-Martinez CE. Adding nebulized corticosteroids to systemic corticosteroids for acute asthma in children: A systematic review with meta-analysis. Pediatr Pulmonol 2020; 55:2508-2517.

2. Hayashi S, Kawada M, Hyakushima N, Saikawa D, Ashitate Y, Suzuki Y, Kawarada Y, Kitashiro S, Tsubota $H$, Okushiba S. Resection of mediastinal goiter extending to the carina with use of artificial pneumothorax, two-lung ventilation, and thoracoscopy, with the patient in a prone position. Gen Thorac Cardiovasc Surg 2019; 67:561-565.

3. Liddy W, Netterville JL, Soylu S, et al. Surgery of Cervical and Substernal Goiter[M]// Surgery of the Thyroid and Parathyroid Glands. 2021.

4. Garcia-Alva $R$, Bobadilla-Rosado LO, Arzola $L H$, Escobar-Preciado M, Anaya-Ayala JE, Hinojosa CA. A case report of a concomitant total thyroidectomy and carotid body tumor resection in a 43-year-old female. Int J Surg Case Rep 2018; 53:17-20.

5. Garcia-Alva R, Bobadilla-Rosado LO, Arzola LH, Escobar-Preciado M, Anaya-Ayala JE, Hinojosa CA. A Case report of a concomitant total thyroidectomy and carotid body tumor resection in a 43-year-old female. Int J Surg Case Rep 2018; 53:17-20.

6. Wojtczak B, Aporowicz M, Kaliszewski K, Bolanowski M. Consequences of bleeding after thyroid surgery analysis of 7805 operations performed in a single center. Arch Med Sci 2018; 14:329-335.

7. World Medical Association. World Medical Association Declaration of Helsinki: ethical principles for medical research involving human subjects. JAMA 2013 27;310(20):2191-4.

8. Patel $R$, Almourani $R$, Srinath $M$, Uraizee $A$, Nayyar $M$, Brietzke S, Regunath H, Gardner M. SUN-574 Exogenous lodine Supplementation-Induced Thyroid Storm in a Patient with Multinodular Goiter. J Endocr Soc: Supplement_1.

9. Lari E, Burhamah W, Lari A, Alsafran S, Ismail A. Amyloid goiter - A rare case report and literature review. Ann Med Surg (Lond) 2020; 57:295-298.

10. Zalazar AM, Rossi JL, José M Moreno Negri, et al. Tiroidectomía transoral endoscópica por abordaje vestibular. Revista Argentina de Cirugía 2020; 112:185188.

11. lijima $Y$, Nakajima $Y$, Kinoshita $H$, Kurihara $Y$, Nishimura $Y$, lizuka $T$, Akiyama $H$, Hirata $T$. Sclerosing thymoma followed up for eight years as mediastinal goiter: A case report. Int J Surg Case Rep 2020; 68:115-118.

12. Delliturri A, Pearl J, Zahir I, Weiss MH, Wiesel $O$. Follicular Thyroid Carcinoma Presenting as a Manubrium Mass. JAMA Otolaryngol Head Neck Surg 2019;145:581-583.

13. Peluso G, Masone S, Campanile S, et al. Incidental thyroid papillary microcarcinoma on 1777 surgically treated patients for benign thyroid disease: $A$ monoinstitutional experience and literature review. Memo 2020;13.

14. Rajan S, Tosh P, Paul J, Kumar L. Effect of inhaled budesonide suspension, administered using a metered dose inhaler, on post-operative sore throat, hoarseness of voice and cough. Indian J Anaesth 2018; 62:66-71.

15. Harounian J, Postevka E, Jamal N. Medications and the larynx. Curr Opin Otolaryngol Head Neck Surg 2019; 27:482-488.

16. Parthasarathy $S$, Nag $K$, Sivashanmugham $T$, Karthikeyan P, Ravishankar M. Anesthetic management of excision of laryngocele-role of transtracheal jet

Trop J Pharm Res, November 2021; 20(11): 2399 
ventilation. J Anaesthesiol Clin Pharmacol 2018; 34:124-125.

17. O'Byrne PM, FitzGerald JM, Bateman ED, Barnes $P J$, Zhong $N$, Keen $C$, Jorup C, Lamarca R, Ivanov $S$, Reddel HK. Inhaled Combined Budesonide-Formoterol as Needed in Mild Asthma. N Engl J Med 2018; 378:1865-1876.

18. Seitz HJ. The influence of budesonide on patients undergoing goiterectomy. The Biochem J, 2019. 